\title{
Sustained Attention and Planning Deficits but Intact Attentional Set-Shifting in Neuroleptic- Naïve First-Episode Schizophrenia Patients
}

\author{
Caroline C. Hilti Tarik Delko Ariane T. Orosz Kathrin Thomann \\ Stephan Ludewig Mark A. Geyer Franz X. Vollenweider Joram Feldon \\ Katja Cattapan-Ludewig
}

Research Department, Psychiatric Services Aargau, Brugg, Switzerland

\section{Key Words}

Cognition • Planning • Sustained attention · Set-shifting •

First-episode schizophrenia • Neuroleptic naïve ·

Medication naïve

\begin{abstract}
Introduction: The nature of deficits in tests of sustained attention, planning and attentional set-shifting has not been investigated in neuroleptic-naïve first-episode (FE) schizophrenia patients. Based on previous literature of chronic and medicated FE schizophrenia patients, we predicted that the neuroleptic-naïve patients would show deficits in these cognitive processes. Methods: Twenty-nine neuroleptic-naïve FE schizophrenia patients and 33 healthy controls - matched by age, gender, and nicotine consumption - performed 3 tests from the Cambridge Automated Neuropsychological Test Battery (CANTAB) thought to measure these cognitive processes: the Rapid Visual Information Processing task (RVIP, sustained attention), the Stockings of Cambridge task (SOC, planning), and the Intradimensional/Extradimensional set-shifting task (IDED, attention shifting). Results: The patients were significantly impaired in the sensitivity index $\left(A^{\prime}\right)$ of the RVIP, and in the number of problems solved with minimum moves on the SOC. Nevertheless, the groups did not differ regarding the number of participants who failed at the crucial extradimensional shift stage of the IDED. Conclusion: Sustained attention and planning abilities are already im-
\end{abstract}

paired in neuroleptic-naïve FE schizophrenia patients, whereas set-shifting abilities as measured with the IDED task seem to be intact at illness onset. Since chronic schizophrenia patients have been shown to have impaired IDED performance, we tentatively propose that IDED performance deteriorates over time with illness chronicity and/or medication.

Copyright $\odot 2009$ S. Karger AG, Basel

\section{Introduction}

Cognitive impairment seems to be a core feature of schizophrenia. For instance, sustained attention, planning and attentional set-shifting belong to the core deficits as defined by MATRICS (Measurement and Treatment Research to Improve Cognition in Schizophrenia [1]). Importantly, sustained attention as well as problem solving are crucial for everyday functioning [2], and are said to be predictive of patients' functional outcomes [3-7].

Neuropsychological tests from the Cambridge Neuropsychological Test Automated Battery (CANTAB) allow a detailed examination of these cognitive functions, as this battery parses the individual's test performance into fundamental cognitive processes [8] that are linked to partially known neuroanatomical substrates [9-12]. Therefore, in the present study, we particularly focused on the CANTAB tests of sustained attention (Rapid Vi-

\section{KARGER}

(C) 2009 S. Karger AG, Basel

Fax +4161306 1234

E-Mail karger@karger.ch

www.karger.com
Accessible online at: www.karger.com/nps
Caroline C. Hilti

University Hospital of Psychiatry Bern

Bolligenstrasse 111, CH-3000 Bern 60 (Switzerland)

Tel. +41 3193283 62, Fax +41319309961

E-Mail caroline.hilti@puk.unibe.ch 
sual Information Processing task; RVIP), planning (Stockings of Cambridge task; SOC), and attention shifting (Intradimensional/Extradimensional set-shifting task; IDED).

These 3 cognitive tasks have already been investigated in chronic schizophrenia and medicated first-episode (FE) schizophrenic patients. Poor performance on the RVIP has been revealed in chronic schizophrenia [13], and in 11 medicated patients in the prodromal phase [14]. However, the small sample size, poor psychopathological characterization, and the comparison with a normative database of healthy volunteers are the constraints of the latter study. Impaired performance on the SOC in terms of fewer perfect solutions and abnormal thinking times has been found in chronic $[12,15,16]$ as well as in medicated FE schizophrenia patients $[8,17]$. In addition, whereas chronic schizophrenia patients have been shown to be strongly impaired on the IDED $[18,19]$ - thought to measure rule acquisition and flexibility of attention [20] - medicated FE schizophrenia patients were relatively unimpaired on all IDED measures except one $[8,17]$. Significantly more medicated FE patients than controls failed at the extradimensional (ED) stage, where subjects need to switch attention from a previously reinforced dimension to a newly reinforced dimension.

Whether or not impairments in these cognitive functions are already evident in neuroleptic-naïve FE schizophrenia patients has not yet been established. Such a sample of patients is crucial to exclude potentially confounding effects of illness chronicity and long-term medication. Especially in the case of IDED performance, it seems possible that deficits might only emerge with illness progression. Thus, we hypothesized that neuroleptic-naïve FE patients would demonstrate a significantly worse sensitivity index $\left(\mathrm{A}^{\prime}\right)$ on the RVIP and would solve fewer SOC problems with minimum moves than healthy controls. Moreover, we hypothesized that significantly more patients than healthy controls would fail at the crucial ED stage of the IDED. Additionally, we descriptively analysed - for the first time to the best of our knowledge whether IDED performance changes after the first 2 months of illness progression and medication.

\section{Materials and Methods}

\section{Participants}

Thirty-eight FE schizophrenia patients were recruited. The diagnosis schizophrenic, schizophreniform, or schizoaffective disorder (according to ICD-10 and DSM-IV diagnostic criteria) was based on DIA-X, a structured clinical interview [21]. Nine patients with past or current antipsychotic medication were excluded. Thus, 29 neuroleptic-naïve FE schizophrenia patients were included in the final analyses. The Positive and Negative Syndrome Scale (PANSS; [24]) was used to assess the patients psychopathologically. Recruitment took place between January 2000 and December 2003 at the Psychiatric Services of Aargau or via outpatient psychiatrists in the canton of Aargau, Switzerland.

Thirty-three healthy controls were recruited through advertisements, and screened according to DSM-IV and ICD-10 using the computerized DIA-X interview [21]. Exclusion criteria were any psychiatric treatments, a personal mental disorder, and mental disorders in first-degree relatives.

Exclusion criteria for both groups were a neurological disease, head injury, and substance dependence (except for nicotine and cannabis consumption). Please refer to table 1 for more demographic and psychopathological characteristics. The study was approved by the ethics committee of the canton of Aargau, and all participants gave their written informed consent.

Neuropsychological Assessment

Both groups performed the RVIP, SOC, and IDED of the CANTAB.

Rapid Visual Information Processing

White numbers from 2 to 9 appear in a pseudo-random order inside a white frame in the center of the black computer screen. Each number is presented for $600 \mathrm{~ms}$ without an interstimulus interval between successive numbers. For approximately $3 \mathrm{~min}$, subjects have to detect 3 target sequences (2-4-6, 3-5-7 and 4-6-8) and respond (within 1,800 $\mathrm{ms}$ after the onset of the last number) using a press pad when they see the last number $(6,7$ and 8 , respectively). Sixteen target sequences occur every $2 \mathrm{~min}$. The subjects were instructed to detect as many target sequences (27 in total) as possible.

We analysed the sensitivity, which is composed of the probability of hits and false alarms (FA), the number of hits and FA, the mean latency, as well as the response criterion $\left(\mathrm{B}^{\prime \prime}\right)$ reflecting the individual's response tendency.

Stockings of Cambridge

The SOC requires subjects to plan and execute a series of 'think ahead' problems. Two displays consisting of 3 stockings each are shown on a computer touch screen. Three balls are distributed in both the upper and the lower stocking displays. The placement of the balls in the upper display is the template for the lower display. Thus, the subjects are requested to move the balls in the lower display until the 3 balls are located at the same places as indicated in the upper display. Before moving the balls, the subjects are asked to plan their moves ahead and to use as few moves as possible in order to copy the upper display. After this initial thinking time, subjects start moving the balls. Initially, 2 moves are needed to copy the upper display, thereafter, difficulty is increased stepwise up to 5 moves. In total, 12 planning problems are presented.

We analysed the number of problems solved within the minimum moves (perfectly solved problems), the number of mean moves needed to solve a problem, the initial thinking time (time needed to plan the problem before the first move), and the subsequent thinking time (time needed from the first move to the last move). 
Table 1. Demographic and psychopathological characteristics of the participants

\begin{tabular}{|c|c|c|c|c|}
\hline & $\begin{array}{l}\text { Neuroleptic-naïve FE } \\
\text { patients }(n=29)\end{array}$ & $\begin{array}{l}\text { Healthy controls } \\
(\mathrm{n}=33)\end{array}$ & $\mathrm{t}, \mathrm{U}, \chi^{2}$ & $\mathrm{p}$ \\
\hline Age, years ${ }^{1}$ & $22.0 \pm 4.0$ & $23.2 \pm 2.8$ & $\mathrm{t}=1.38$ & n.s. \\
\hline Age range, years & $18-32$ & $18-31$ & & \\
\hline Cigarettes smoked per day ${ }^{1}$ & $17.4 \pm 9.9$ & $15.3 \pm 5.0$ & $\mathrm{U}=777.5$ & n.s. \\
\hline Vocabulary test (MWT) $)^{1,2}$ & $23.1 \pm 5.8$ & $28.0 \pm 4.2$ & $\mathrm{U}=191.0$ & $<0.01$ \\
\hline Years of education 1,2 & $9.5 \pm 1.3$ & $12.7 \pm 1.5$ & $\mathrm{U}=120.5$ & $<0.001^{2}$ \\
\hline PANSS positive symptoms ${ }^{3}$ & $17.1 \pm 5.3$ & & & \\
\hline PANSS negative symptoms ${ }^{3}$ & $14.5 \pm 4.5$ & & & \\
\hline PANSS general psychopathology 3 & $35.5 \pm 7.1$ & & & \\
\hline Females $^{1}$ & $5(17.2)$ & $9(27.3)$ & $\chi^{2}=0.89$ & n.s. \\
\hline Nonsmokers & $5(17.2)$ & $3(9)$ & $\chi^{2}=0.91$ & n.s. \\
\hline Secondary school level of education ${ }^{1,2}$ & $25(86.2)$ & $8(24.2)$ & $\chi^{2}=25.8$ & $<0.00001$ \\
\hline
\end{tabular}

Data presented as means $\pm \mathrm{SD}$, where indicated; parentheses contain percentages. MWT $=$ Mehrfachwahl-Wortschatz Test; PANSS = Positive and Negative Syndrome Scale.

${ }^{1}$ Controls and patients were matched for age, gender, and nicotine consumption, as nicotine has been shown to influence cognitive performance [22]. However, the groups differed concerning MWT points ( $n=26$ patients; $n=29$ healthy controls), years of education and level of education. The finding of a significant difference in verbal IQ (MWT) between the 2 groups is in line with Jazbec et al. [18] and Birkett et al. [23]. Moreover, several studies have shown that individuals who will suffer from schizophrenia in the future can undergo deterioration in IQ during early adulthood $[24,25]$ and that children who develop schizophrenia in adulthood are half as likely as controls to proceed to high school [26].
${ }^{2}$ According to the number of years of education, participants were classified into 2 levels: (1) secondary school level (8-11 years of scholarly education excluding apprenticeship); (2) a higher school certificate (12-13 years of scholarly education). The level of education and MWT depended on each other as participants with a secondary school level had a significantly lower MWT score than the ones with a higher school certificate $(U=152.5$; $\mathrm{p}<0.001)$. The level of education was thus taken as a covariate in the statistical analyses.

${ }^{3}$ The PANSS scores show that our patients had average symptom scores, comparable with other FE schizophrenic patients samples recruited by Chan et al. [27] and Williams et al. [28].
Intradimensional/Extradimensional Set-Shifting

Two dimensions, namely purple shapes and white lines, are used in this touch screen computer test. Simple stimuli are either shapes or lines, whereas compound stimuli consist of shapes and lines. The test comprises 9 stages with increasing difficulty. Initially, subjects only have to attend to different simple and compound stimuli within the shape dimension, e.g. 2 different shapes are presented either without lines (simple stimulus) or with lines (compound stimulus), and the subject has to switch attention only between these 2 shapes, the lines are irrelevant; these are the intradimensional shifts. In the last and crucial step, subjects are required to shift attention to the previously irrelevant line dimension (extradimensional shifts; EDS). The participant is instructed that he/she has to learn rules throughout the test by discovering which one of 2 presented stimuli is correct. Moreover, the subject knows that when a rule is changed, he/she has to think of a different rule in order to go on doing well.

We analysed the number of participants who completed all stages, the errors up to the extradimensional shift (pre-ED errors), the errors at the extradimensional shift (ED errors), and the total errors adjusted. The latter is a measure of the subject's efficiency in attempting the test, correcting for the fact (i.e. adding 25 to the subject's errors that accumulated up until then) that subjects failing at any stage of the test have less opportunity to make errors.
In order to shed more light on the course of IDED performance, this task was additionally administered to 7 patients and 16 healthy controls approximately 2 months after their first IDED performance. At this time, the 7 patients had been treated with atypical antipsychotics for $71 \pm 15.4$ days (SD) on average.

Other detailed explanations and illustrations of these CANTAB tests can be found in the literature $[8,12,17,29,19]$ and at www.cantabeclipse.com.

\section{Vocabulary Test}

The MWT (Mehrfachwahl-Wortschatz Test or Multiple Choice Vocabulary Test [30]) was used to analyse the participants' pre-morbid verbal IQ. This vocabulary test consists of 37 rows with 5 words each, and the participant has to underline the correct word in each row (table 1).

\section{Statistical Analyses}

SPSS 15 statistical software was used to analyse the data. All data were evaluated for normality of distribution using the Kolmogorov-Smirnov test, parameters for skewness and kurtosis, as well as Q-Q plots. RVIP A', SOC problems solved with minimum moves, and the number of participants completing all stages on the IDED were analysed in a hypothesis-driven manner. The remaining data were analysed descriptively. 
Normally distributed data were analysed using univariate ANCOVAs, including the level of education as a covariate (RVIP $\mathrm{A}^{\prime}$ and SOC problems solved with minimum moves), or Student's $\mathrm{t}$ test (age) to assess group differences.

Non-normally distributed data were analysed using the MannWhitney U test (RVIP FA, RVIP response criterion B"', SOC with 4 mean moves, SOC with 5 mean moves). Data that became normally distributed by rank transformation were analysed using either univariate ANCOVAs (RVIP hits, RVIP mean latency, IDED pre-ED errors, IDED ED errors, and IDED total errors adjusted) or ANCOVAs repeated-measures (SOC initial and subsequent thinking time) with the level of education as a covariate. Dichotomous distributed data were analysed using the $\chi^{2}$ test.

Correlations between RVIP A' and PANSS or SOC problems solved in minimum moves and PANSS (negative, positive and general psychopathology score) were calculated using Spearman correlations.

The effect sizes $\left(\eta^{2}\right)$ for significant results were calculated, and 2 -tailed $\mathrm{p}$ values are reported throughout.

\section{Results}

Means $\pm \mathrm{SD}$ and the number of participants for each measure of the 3 tasks are given in table 2 .

\section{Rapid Visual Information Processing}

As hypothesized, the FE patients were significantly less sensitive $\left(\mathrm{A}^{\prime}\right)$ than the controls $[\mathrm{F}(2,58)=4.3$, $\mathrm{p}<$ 0.05] in the RVIP task. Moreover, the participants with higher education were more sensitive $[\mathrm{F}(2,58)=8.0, \mathrm{p}<$ 0.01]. The results for the hits, FA, mean latency, and response criterion $\mathrm{B}^{\prime \prime}$ were analysed in an exploratory way. The patients made significantly fewer hits $[\mathrm{F}(2,58)=4.4$, $\mathrm{p}<0.05]$. The education effect was also significant $[\mathrm{F}(2$, $58)=8.5, \mathrm{p}<0.05]$. The groups did not differ in FA [U = 467.5, $\mathrm{p}=$ n.s. or $\mathrm{B}^{\prime \prime}[\mathrm{U}=463.0, \mathrm{p}=$ n.s. $]$. The latter observation emphasized that the patients' reduced sensitivity is not attributable to poor motivation. Moreover, the groups did not differ with regard to the mean latency $[\mathrm{F}(2,58)=0.2, \mathrm{p}=\mathrm{n} . \mathrm{s}$. $]$. However, the education effect was significant $[\mathrm{F}(2,58)=5.1, \mathrm{p}<0.05] . \mathrm{A}^{\prime}$ and reaction times correlated significantly in both groups [controls $\mathrm{r}=$ $-0.49, \mathrm{p}<0.01, \mathrm{n}=33$; patients $\mathrm{r}=-0.57, \mathrm{p}<0.01, \mathrm{n}=29$ ], showing that the faster the participant, the higher $\mathrm{A}^{\prime}$.

\section{Stockings of Cambridge}

As predicted, we found that the patients solved fewer SOC problems perfectly than the healthy participants $[\mathrm{F}(2,56)=8.2, \mathrm{p}<0.01]$. The education level did not have a significant effect. Analyses of the mean moves, initial thinking times, and subsequent thinking times were done descriptively. The patients needed significantly more mean moves than the controls in the 4-move [U = 262.5, $\mathrm{p}<0.01]$ and 5-move $[\mathrm{U}=217.5, \mathrm{p}<0.001]$ conditions. For the initial thinking times, the group effect was non-significant $[\mathrm{F}(2,56)=0.59, \mathrm{p}=\mathrm{n} . \mathrm{s}$.] , but the initial thinking times increased with difficulty $[\mathrm{F}(3,168)=18.1$, $\left.\mathrm{p}<10^{-9}\right]$. Moreover, the group $\times$ condition interaction $[\mathrm{F}(3,168)=3.4, \mathrm{p}<0.05]$ was significant. The education effect was not significant. Concerning the subsequent thinking times, the group effect $[\mathrm{F}(1,56)=7.4, \mathrm{p}<0.01]$ and condition effect $[\mathrm{F}(3,168)=4.0, \mathrm{p}<0.01]$ were significant. However, neither the interaction time $\times$ group nor the education effect were significant. Thus, the patients, as compared to the healthy volunteers, thought longer during the execution of the moves.

The number of moves in the 5-move condition correlated negatively with the initial thinking time $[\mathrm{r}=-0.44$, $\mathrm{p}<0.05]$ and with the subsequent thinking time $[\mathrm{r}=$ $-0.59, \mathrm{p}<0.001]$ in the controls. Thus, the longer the controls thought before and during execution of the problem, the fewer mean moves they needed in this condition. In the patients, however, the number of mean moves in the 5-move condition did not correlate with the corresponding initial thinking time $[\mathrm{r}=-0.16, \mathrm{p}=\mathrm{n} . \mathrm{s}$. $]$, but rather with the corresponding subsequent thinking time $[\mathrm{r}=$ $-0.59, \mathrm{p}<0.01]$.

\section{Intradimensional/Extradimensional Set-Shifting}

The participants either completed all 9 stages or failed at the ED stage (1 patient completed 8 of 9 stages, and was hence excluded from the $\chi^{2}$ test ). The $\chi^{2}$ test then revealed a trend that fewer patients than controls completed all 9 stages $\left[\chi^{2}=3.3, \mathrm{p}<0.07\right]$ (fig. 1 ) The pre-ED errors, the ED errors, and the total errors adjusted were analysed in an exploratory manner. We did not find a group difference in the pre-ED errors $[\mathrm{F}(2,58)=0.1, \mathrm{p}=$ n.s.] or $\operatorname{ED}$ errors $[\mathrm{F}(2,58)=2.9, \mathrm{p}=$ n.s.], but a trend for more total errors adjusted in the patient group $[\mathrm{F}(2,58)=$ $3.8, \mathrm{p}=0.056]$. The education effect was not significant in any of the 3 analyses.

Further analyses with 7 patients and 16 controls who were re-measured a second time after $65.8 \pm 10.8$ days on average after the 'baseline' testing (the patients were medicated for $71 \pm 15.4$ days on average) were then carried out. At this time, the 7 patients were medicated with risperidone $(\mathrm{n}=2: 1$ and $4 \mathrm{~g} /$ day $)$, quetiapine $(\mathrm{n}=3: 200$, 400 , and $600 \mathrm{mg} / \mathrm{day}$ ), amisulpride ( $\mathrm{n}=1: 400 \mathrm{mg} / \mathrm{day})$ or olanzapine ( $\mathrm{n}=1: 5 \mathrm{mg} /$ day). Significantly fewer patients completed all stages at the second testing when compared to the controls $\left[\chi^{2}=11.1, \mathrm{p}<0.01\right]$, whereas the same effect was not evident at baseline with the same individuals 
Table 2. Means \pm SD and statistical values of RVIP, SOC and IDED data

\begin{tabular}{|c|c|c|c|c|c|c|c|}
\hline & \multicolumn{2}{|c|}{$\begin{array}{l}\text { Neuroleptic-naïve FE } \\
\text { patients }\end{array}$} & \multicolumn{2}{|c|}{ Healthy controls } & \multicolumn{2}{|c|}{ Group differences } & \multirow[t]{2}{*}{$\begin{array}{l}\text { Effect } \\
\text { size, } \eta^{2}\end{array}$} \\
\hline & $\mathrm{n}$ & means $\pm S D$ & $\mathrm{n}$ & means $\pm S D$ & $\mathrm{~F}, \mathrm{t}, \mathrm{U}$ & $\mathrm{p}$ & \\
\hline \multicolumn{8}{|l|}{ RVIP } \\
\hline \multirow[t]{2}{*}{ Sensitivity index A' } & 28 & $0.862 \pm 0.055^{1}$ & 33 & $0.925 \pm 0.044^{1}$ & \multirow[t]{2}{*}{$\mathrm{F}=4.3$} & \multirow{2}{*}{$<0.05$} & \multirow[t]{2}{*}{0.37} \\
\hline & 28 & $0.878^{2}$ & 33 & $0.911^{2}$ & & & \\
\hline Hits, n out of 27 & 28 & $12.3 \pm 5.9^{1}$ & 33 & $19 \pm 4.7^{1}$ & $\mathrm{~F}=4.4$ & $<0.05$ & 0.38 \\
\hline False alarms, $\mathrm{n}$ & 19 & $0.3 \pm 0.5^{1}$ & 33 & $0.5 \pm 1.3^{1}$ & $\mathrm{U}=467.5$ & n.s. & \\
\hline Mean latency, ms & 28 & $487.7 \pm 125.6^{1}$ & 33 & $433.1 \pm 77.2^{1}$ & $\mathrm{~F}=0.2$ & n.s. & \\
\hline Response criterion $\mathrm{B}^{\prime \prime}$ & 29 & $0.988 \pm 0.021^{1}$ & 32 & $0.982 \pm 0.041^{1}$ & $\mathrm{U}=463.0$ & n.s. & \\
\hline \multicolumn{8}{|l|}{ SOC } \\
\hline \multirow[t]{2}{*}{ Problems solved in minimum moves, $\mathrm{n}$ out of 12} & 26 & $8.5 \pm 1.9^{1}$ & 33 & $10.24 \pm 1.3^{1}$ & \multirow{2}{*}{$\mathrm{F}=8.2$} & \multirow[t]{2}{*}{$<0.01$} & \multirow[t]{2}{*}{0.22} \\
\hline & 26 & $8.6^{2}$ & 33 & $10.2^{2}$ & & & \\
\hline \multicolumn{8}{|l|}{ Mean moves, $\mathrm{n}$} \\
\hline 2 moves & \multirow[t]{4}{*}{27} & $2.0 \pm 0.2^{1}$ & \multirow[t]{4}{*}{33} & $2.0 \pm 0.0^{1}$ & & & \\
\hline 3 moves & & $3.3 \pm 0.4^{1}$ & & $3.1 \pm 0.2^{1}$ & & & \\
\hline 4 moves & & $5.3 \pm 1.0^{1}$ & & $4.6 \pm 0.7^{1}$ & $\mathrm{U}=262.5$ & $<0.01$ & \\
\hline 5 moves & & $6.6 \pm 1.2^{1}$ & & $5.6 \pm 0.7^{1}$ & $\mathrm{U}=217.5$ & $<0.001$ & \\
\hline \multicolumn{8}{|l|}{ Initial thinking time, ms } \\
\hline 2 moves & \multirow[t]{4}{*}{26} & $1,565 \pm 1,348^{1}$ & \multirow[t]{4}{*}{33} & $1,566 \pm 751^{1}$ & \multirow{4}{*}{$\begin{array}{l}\text { Group } \\
\mathrm{F}=0.59\end{array}$} & \multirow[t]{4}{*}{ n.s. } & \\
\hline 3 moves & & $5,829 \pm 4,122^{1}$ & & $4,168 \pm 2,052^{1}$ & & & \\
\hline 4 moves & & $8,319 \pm 6,395^{1}$ & & $9,684 \pm 6,207^{1}$ & & & \\
\hline 5 moves & & $10,714 \pm 6,633^{1}$ & & $12,688 \pm 5,916^{1}$ & & & \\
\hline \multicolumn{8}{|l|}{ Subsequent thinking time, ms } \\
\hline 2 moves & \multirow[t]{4}{*}{26} & $255 \pm 662^{1}$ & \multirow[t]{4}{*}{33} & $33 \pm 87^{1}$ & \multirow{4}{*}{$\begin{array}{l}\text { Group } \\
\mathrm{F}=7.4\end{array}$} & \multirow[t]{4}{*}{$<0.01$} & \\
\hline 3 moves & & $811 \pm 1,636^{1}$ & & $73 \pm 155^{1}$ & & & \\
\hline 4 moves & & $1,307 \pm 1,395^{1}$ & & $685 \pm 1,398^{1}$ & & & \\
\hline 5 moves & & $1,232 \pm 1,536^{1}$ & & $743 \pm 1,166^{1}$ & & & \\
\hline \multicolumn{8}{|l|}{ IDED } \\
\hline Number of participants completing all stages ${ }^{3}$ & 28 & 16 & 33 & 26 & $\chi^{2}=3.3$ & 0.07 & \\
\hline Pre-ED errors, $n$ & 28 & $8.8 \pm 9.4^{1}$ & 33 & $7.1 \pm 3.7^{1}$ & $\widehat{F}=0.1$ & n.s. & \\
\hline ED errors, $\mathrm{n}$ & 28 & $13.7 \pm 10.6^{1}$ & 33 & $11.2 \pm 10.0^{1}$ & $\mathrm{~F}=2.9$ & n.s. & \\
\hline Total errors adjusted, $\mathrm{n}$ & 28 & $35.1 \pm 24.7^{1}$ & 33 & $25.1 \pm 18.5^{1}$ & $\mathrm{~F}=3.8$ & 0.056 & 0.06 \\
\hline \multicolumn{8}{|l|}{$\begin{array}{l}{ }^{1} \text { Uncorrected value. } \\
{ }^{2} \text { Value corrected for the covariate education level. }\end{array}$} \\
\hline
\end{tabular}

$\left[\chi^{2}=0.3, p=\right.$ n.s. $]$. As a second critical measure, the total errors adjusted were analysed descriptively. They increased in the patients from $27.6 \pm 19.7$ up to $45.4 \pm 19.1$ errors and decreased in the control group from $22.6 \pm$ 18.0 down to $11.8 \pm 7.6$ errors from baseline to the second test session. However, a repeated-measures ANCOVA revealed a trend for a group effect $[F(1,20)=3.5, p=$ $0.074]$, but no condition effect $[\mathrm{F}(1,20)=0.5, \mathrm{p}=$ n.s. $]$ nor interaction effect $[\mathrm{F}(1,20)=1.8, \mathrm{p}=$ n.s.]. Additional Spearman correlations between the total errors adjusted and the days of medication, as well as between total errors adjusted and the equivalent chlorpromazine dose of the individual's antipsychotic medication, were not significant.

Correlations between PANSS and Cognitive Measures

Correlations between RVIP A' or SOC problems solved with minimum moves with negative or positive symptoms of the PANSS were all not significant. 


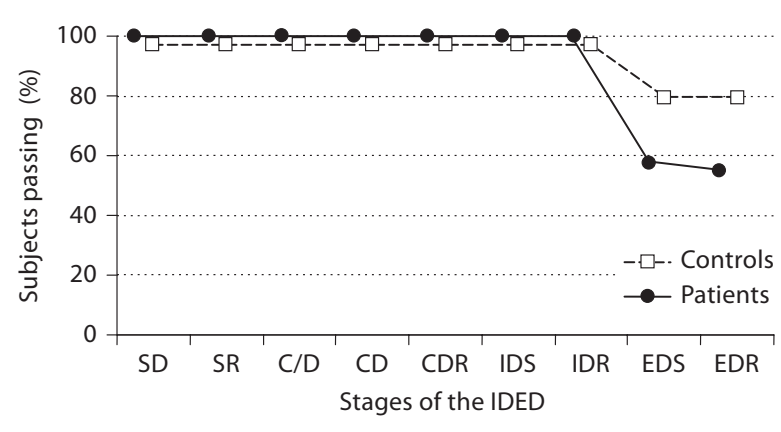

Fig. 1. The percentage of subjects passing each stage of the IDED. All 29 patients $(\bullet)$ and 33 healthy volunteers $(\square)$ managed the test up to the ED stage, i.e. no difficulties were present at the intradimensional shift stages. There was a trend $\left(\chi^{2}=3.3, p<0.07\right)$ that fewer patients $(55.1 \%)$ completed the whole test when compared to the controls (78.7\%). Thus, most participants failed at the ED stage - except 1 patient who failed only at stage 8 . The stages are simple discrimination (SD), simple discrimination reversal (SR), compound discrimination stages (C/D and CD), compound discrimination reversal (CDR), intradimensional shift (IDS), intradimensional shift reversal (IDR), extradimensional shift (EDS), and extradimensional shift reversal (EDR).

\section{Discussion}

The present study investigated cognitive performance in neuroleptic-naïve FE schizophrenia patients on the RVIP, SOC, and IDED tests from the CANTAB battery. The results show that sustained attention and planning are indeed impaired in neuroleptic-naïve FE schizophrenia patients, just as reported in chronic schizophrenia patients $[12,13,15]$. In contrast, attentional set-shifting, which has also been shown to be impaired in chronic schizophrenia patients $[18,19]$, seems to be intact at the onset of the illness.

The finding of impaired sustained attention (RVIP) in neuroleptic-naïve FE schizophrenia patients is in accordance with findings in chronic schizophrenia patients [13] and patients in the prodromal phase [14]. The present RVIP data corroborate other studies suggesting that sustained attention, as measured with various continuous performance tasks (CPT), is impaired in schizophrenia patients at all stages of the illness [23, 31-33]. It should be noted, however, that the RVIP and most continuous performance tasks depend upon not only sustained attention, but also additional capacities such as working memory (WM). Poor performance on the RVIP could there- fore be explained by problems with context information in WM and/or slowing of information processing. Referring to the first issue, context information in the case of the RVIP could be task-relevant information that consists of the 3 target sequences and their behavioral rules. This RVIP-specific contextual information must be updated by incoming numbers, could control performance, and would be required for a motor response $[31,34]$. We therefore propose that impairments in maintaining and rapidly updating these rules, as well as problems in rapidly screening numbers, could account for RVIP problems. Referring to the second issue, Elvevag and Goldberg [35] and Elvevag et al. [36] suggested that schizophrenia patients may not be able to process information with a high moment-to-moment demand. Similarly, Townsend et al. [37] proposed that schizophrenia patients could suffer from a general slowing of processing speed. Our findings of comparable reaction times as well as the negative correlation between reaction times and sensitivity in patients and controls, however, do not support these suggestions. This latter result shows that participants who can process information more quickly than others are more efficient in detecting target sequences or ignoring irrelevant numbers. Such rapid processing might be beneficial for task performance, as these individuals might be better able to remain on task and less likely to overlook target sequences.

On the SOC, the FE patients produced fewer perfect solutions and required significantly more moves in the 4- and 5-move conditions to solve a problem than controls. These observations are in accordance with findings in medicated FE $[8,17,38,39]$ and chronic schizophrenia $[12,15,16]$ patients. Thus, planning disturbances already exist at the onset and continue throughout the illness. Moreover, the patients had comparable initial thinking times but slower subsequent thinking times than the controls. Such a pattern of poor performance could be due to insufficient planning ahead and/or impaired WM. First, good performance on the SOC requires that the subject plan ahead. Schizophrenia patients have been said to attempt to solve problems without adequate forethought because the patients exhibited faster initial thinking times than controls $[17,19]$. However, we found comparable initial thinking times, suggesting that our patients planned better than medicated FE patients. Nevertheless, the lack of a negative correlation between the initial thinking time and the mean moves for the 5 -move condition - evident in our control group but not in our patient group - might reflect a subtle problem in planning ahead. Moreover, as both groups had fewer mean moves when 
they thought longer during the execution of the 5-move problem, we suggest that the patients planned better during the execution of the moves (i.e. subsequent thinking time) than before the execution of the moves. Second, impaired WM might account for SOC problems, insofar as prolonged subsequent thinking times as well as elevated mean moves might be due to slowed information processing in WM. Indeed, Huddy et al. [39] found that the FE patients' impaired planning on the SOC was due to increased duration of gaze periods. Hence, they proposed that a slowing of information processing in WM could render perceptual representation vulnerable to interference and result in more errors while executing the moves. In the 4- and 5-move conditions in particular, patients might be confronted with a loss of their plan, and therefore have to spend extra time searching for a solution [19].

On the IDED task, the ED stage, where subjects must switch attention between 2 dimensions, is a critical step. Indeed, the participants who did not complete all 9 stages, all failed (with 1 exception) at this crucial ED stage. However there was only a trend that significantly more patients than controls did not complete all stages. Hutton et al. [8] and Joyce et al. [17], in contrast, reported that significantly more medicated FE patients failed the task. The results of this measure should be interpreted cautiously as the controls' performance varies strongly between studies, and is therefore thought to influence the outcome of group comparisons. For instance, whereas $55 \%$ of our patients compared to $79 \%$ of the healthy volunteers accomplished the whole task, Hutton et al. [8] reported that $75 \%$ of medicated FE schizophrenia patients vs. $100 \%$ of the controls completed the IDED. The number of errors made at the ED stage is a critical measure of attentional set-shifting ability [29]. However, our neuroleptic-naïve FE patients did not make more ED errors, which is consistent with findings by Hutton et al. [8] and Joyce et al. [17]. We therefore propose that our patients do not have substantial problems in shifting attention between 2 dimensions (ED stage). Moreover, they are also able to shift attention within (pre-ED stages) a dimension, since they did not have more pre-ED errors. Despite these findings, our patients tended to make more total errors than the controls, which might nevertheless reflect slight difficulties in adjusting to new stimuli throughout the test. Thus, we did not find any IDED measure that revealed a significant group difference between healthy controls and neuroleptic-naïve FE patients.
Since chronic schizophrenia patients are considerably impaired on many of the previously mentioned IDED measures [18, 19, 40, 41], whereas medicated FE patients $[8,17]$ and siblings of schizophrenia patients [41] are said to be relatively unimpaired, it seems that IDED impairments develop over time as a consequence of chronicity and/or medication. In fact, our exploratory analyses including 7 patients and 16 controls who were re-tested a second time, points towards a deterioration in IDED performance regarding the number of participants completing all stages and the total errors adjusted. These results however need to be interpreted cautiously due to the small sample size.

The strengths of this study are a relatively large group of neuroleptic-naïve FE schizophrenia patients, the use of automated tests minimizing problems with accuracy and consistency of administration, and the matching for nicotine consumption. The main limitation of the study is that the control and patient group differed significantly in the level of education and pre-morbid verbal IQ.

Taken together, cognitive deficits in sustained attention and planning already seem to be present at early stages of schizophrenia independently of chronicity and medication, whereas patients' set-shifting ability on the IDED is intact. An intact functioning of WM (encoding, maintaining, and manipulating of information), which was also shown to be impaired in schizophrenia patients, might be more crucial for SOC and RVIP performance than for IDED performance. This in turn could be a reason that IDED seems to be intact at illness onset. Moreover, we tentatively propose that deficits in set-shifting performance appear to emerge in association with illness chronicity and/or medication. The course of cognitive performance in these tasks needs to be thoroughly investigated in a follow-up study with schizophrenic patients before and after some months or years of medication. The findings may have some relevance for the development of novel treatments, in particular they indicate that procognitive medications should be developed for improving attentional and planning performance.

\section{Acknowledgements}

This study was supported by a grant from NARSAD Young Investigators Award 2003 and an Investigator-Initiated Research Grant, Eli Lilly Suisse (given to K.C.L.) and by the US Veterans Administration VISN 22 Mental Illness Research, Education, and Clinical Centre (M.A.G.). We thank our statistician Pietro Ballinari for his help and guidance in analysing the data. 


\section{References}

$\checkmark 1$ Nuechterlein KH, Barch DM, Gold JM, Goldberg TE, Green MF, Heaton RK: Identification of separable cognitive factors in schizophrenia. Schizophr Res 2004;72:29-39.

$\checkmark 2$ Green MF, Kern RS, Heaton RK: Longitudinal studies of cognition and functional outcome in schizophrenia: implications for MATRICS. Schizophr Res 2004;72:41-51.

$\checkmark 3$ Green MF: What are the functional consequences of neurocognitive deficits in schizophrenia? Am J Psychol 1996;153:321-330.

4 McGurk SR: Neurocognition as a determinant of employment status in schizophrenia. J Psychiatr Pract 2000;6:190-196.

5 Revheim N, Medalia A: Verbal memory, problem-solving skills and community status in schizophrenia. Schizophr Res 2004;68: 149-158.

-6 Prouteau A, Verdoux H, Briand C, Lesage A, Lalonde P, Nicole L, Reinharz D, Stip E: Cognitive predictors of psychosocial functioning outcome in schizophrenia: a follow-up study of subjects participating in a rehabilitation program. Schizophr Res 2005;77:343-353.

$>7$ Prouteau A, Verdoux H, Briand C, Lesage A, Lalonde P, Nicole L, Reinharz D, Stip E: The crucial role of sustained attention in community functioning in outpatients with schizophrenia. Psychiatry Res 2004;15:171-177.

$\checkmark 8$ Hutton SB, Puri BK, Duncan LJ, Robbins TW, Barnes TR, Joyce EM: Executive function in first-episode schizophrenia. Psychol Med 1998;28:463-473.

9 Levaux MN, Potvin S, Sepehry AA, Sablier J, Mendrek A, Stip E: Computerized assessment of cognition in schizophrenia: promises and pitfalls of CANTAB. Eur Psych 2007;22:104-115.

-10 Rogers RD, Andrews TC, Grasby PM, Brooks DJ, Robbins TW: Contrasting cortical and subcortical activations produced by attentional-set shifting and reversal learning in humans. J Cogn Neurosci 2000;12:142-162.

$\checkmark 11$ Owen AM, Roberts AC, Polkey CE, Sahakian BJ, Robbins TW: Extra-dimensional versus intra-dimensional set shifting performance following frontal lobe excisions, temporal lobe excisions or amygdalo-hippocampectomy in man. Neuropsychologia 1991;29:993-1006.

-12 Pantelis C, Barnes TR, Nelson HE, Tanner S, Weatherley L, Owen AM, Robbins TW: Frontal-striatal cognitive deficits in patients with chronic schizophrenia. Brain 1997;120: 1823-1843.

$\checkmark 13$ Cattapan-Ludewig K, Hilti CC, Ludewig S, Vollenweider FX, Feldon J: Rapid visual information processing in schizophrenic patients: the impact of cognitive load and duration of stimulus presentation. A pilot study. Neuropsychobiology 2005;52:130-134.

- 14 Bartok E, Berecz R, Glaub T, Degrell I: Cognitive functions in prepsychotic patients. Prog Neuropsychopharmacol Biol Psych 2005;29:621-625.
15 Morris RG, Rushe T, Woodruff PWR, Murray $\mathrm{RM}$ : Problem solving in schizophrenia: a specific deficit in planning ability. Schizophr Res 1995;14:235-246.

16 Schuepbach D, Weber S, Kawohl W, Hell D: Impaired rapid modulation of cerebral hemodynamics during a planning task in schizophrenia. Clin Neurophysiol 2007;118: 1449-1459.

17 Joyce E, Hutton S, Mutsatsa S, Gibbins H, Webb E, Paul S, Robbins T, Barnes T: Executive dysfunction in first-episode schizophrenia and relationship to duration of untreated psychosis: the West London Study. Br J Psychol 2002;181:38-44.

18 Jazbec S, Pantelis C, Robbins T, Weickert T, Weinberger DR, Goldberg TE: Intra-dimensional/extra-dimensional set-shifting performance in schizophrenia: impact of distractors. Schizophr Res 2007;89:339-349.

19 Tyson PJ, Laws KR, Roberts KH, Mortimer AM: Stability of set-shifting and planning abilities in patients with schizophrenia. Psychiatry Res 2004;129:229-239.

20 Barnett JH, Sahakian BJ, Werners U, Hill KE, Brazil R, Gallagher O, Bullmore ET, Jones PB: Visuospatial learning and executive function are independently impaired in first-episode psychosis. Psychol Med 2005; 35:1031-1041.

21 Wittchen HU, Pfister H: DIA-X Manual: Instruktionsmanual zur Durchführung von DIAX-Interviews. Frankfurt, Swets \& Zeitlinger B.V. Swets Test Services, 1997.

22 Kumari V, Gray JA, Ffytche DH, Ballard C, Brown RG, Howard R: Cognitive effects of nicotine in humans: an fMRI study. Neuroimage 2003;19:1002-1013.

23 Birkett P, Sigmundsson T, Sharma T, Toulopoulou T, Griffiths TD, Reveley A, Murray R: Reaction time and sustained attention in schizophrenia and its genetic predisposition. Schizophr Res 2007;95:76-85.

24 Rabinowitz J, Reichenberg A, Weiser M, Mark M, Kaplan Z, Davidson M: Cognitive and behavioural functioning in men with schizophrenia both before and shortly after first admission to hospital: cross-sectional analysis. Br J Psychol 2000;177:26-32.

25 Weiser M, Reichenberg A, Rabinowitz J, Kaplan Z, Mark M, Nahon D, Davidson M: Gender differences in premorbid cognitive performance in a national cohort of schizophrenic patients. Schizophr Res 2000;45: 185-190.

26 Cannon M, Jones P, Huttunen MO, Tanskanen A, Huttunen T, Rabe-Hesketh S, Murray RM: School performance in Finnish children and later development of schizophrenia: a population-based longitudinal study. Arch Gen Psychiatry 1999;56:457-463.

27 Chan RCK, Chen EYH, Law CW: Specific executive dysfunction in patients with firstepisode medication-naïve schizophrenia. Schizophr Res 2006;82:51-64.
28 Williams LM, Whitford TJ, Flynn G, Wong W, Liddell BJ, Silverstein S, Galletly C, Harris AW, Gordon E: General and social cognition in first episode schizophrenia: identification of separable factors and prediction of functional outcome using the IntegNeuro test battery. Schizophr Res 2008;99:182-191.

29 Fray PJ, Robbins TW, Sahakian BJ: Neuropsychiatric applications of CANTAB. Int J Geriatr Psychiatry 1996;11:329-336.

30 Lehrl S: Mehrfachwahl-Wortschatz-Intelligenztest (MWT). Erlangen, Perimed, 1977.

-31 Barch DM, Carter CS, Braver TS, Sabb FW, MacDonald A 3rd, Noll DC, Cohen JD: Selective deficits in prefrontal cortex function in medication-naïve patients with schizophrenia. Arch Gen Psychiatry 2001;58:280-288.

-32 Buchanan RW, Strauss ME, Breier A, Kirkpatrick B, Carpenter WT Jr: Attentional impairments in deficit and nondeficit forms of schizophrenia. Am J Psychol 1997;154:363370.

33 Rhinewine JP, Lencz T, Thaden EP, Cervellione KL, Burdick KE, Henderson I, Bhaskar S, Keehlisen L, Kane J, Kohn N, Fisch GS, Bilder RM, Kumra S: Neurocognitive profile in adolescents with early-onset schizophrenia: clinical correlates. Biol Psychiatry 2005; 58:705-712.

34 Cohen JD, Servan-Schreiber D: Context, cortex, and dopamine: a connectionist approach to behavior and biology in schizophrenia. Psychol Rev 1992;99:45-77.

-35 Elvevag B, Goldberg TE: Cognitive impairment in schizophrenia is the core of the disorder. Crit Rev Neurobiol 2000;14:1-21.

>36 Elvevag B, Weinberger DR, Suter JC, Goldberg TE: Continuous performance test and schizophrenia: a test of stimulus-response compatibility, working memory, response readiness, or none of the above? Am J Psychol 2000;157:772-780.

37 Townsend LA, Norman RM, Malla AK, Rychlo AD, Ahmed RR: Changes in cognitive functioning following comprehensive treatment for first episode patients with schizophrenia spectrum disorders. Psychiatry Res 2002;113:69-81.

-38 Joyce EM, Hutton SB, Mutsatsa SH, Barnes TR: Cognitive heterogeneity in first-episode schizophrenia. Br J Psychol 2005;187:516-522.

39 Huddy VC, Hodgson TL, Kapasi M, Mutsatsa SH, Harrison I, Barnes TR, Joyce EM: Gaze strategies during planning in first-episode psychosis. J Abnorm Psychol 2007;116: 589-598.

40 Elliott R, McKenna PJ, Robbins TW, Sahakian BJ: Neuropsychological evidence for frontostriatal dysfunction in schizophrenia. Psychol Med 1995;25:619-630.

-41 Ceaser AE, Goldberg TE, Egan MF, McMahon RP, Weinberger DR, Gold JM: Set-shifting ability and schizophrenia: a marker of clinical illness or an intermediate phenotype? Biol Psychiatry 2008;64:782-788. 